\title{
KAJIAN KELAYAKAN AIR SUNGAI CIKAPUNDUNG SEBAGAI AIR BERSIH
}

\author{
Ginardy Husada ${ }^{1}$, Maria Christine ${ }^{2}$, Maria Fransiska ${ }^{3}$ \\ ${ }^{1}$ Dosen Jurusan Teknik Sipil, Fakultas Teknik, Universitas Kristen Maranatha \\ ${ }^{2}$ Dosen Jurusan Teknik Sipil, Fakultas Teknik, Universitas Kristen Maranatha \\ ${ }^{3}$ Dosen Luar Biasa Jurusan Teknik Sipil, Fakultas Teknik, Universitas Kristen Maranatha
}

\begin{abstract}
ABSTRAK
Saat ini air bersih menjadi langka dan berbagai penyakit yang disebabkan oleh air baku yang sudah terkontaminasi mempengaruhi hampir seluruh penduduk dunia. Indonesia diperkirakan mengalami krisis air bersih pada tahun 2025. Air bawah tanah kota Bandung juga dinyatakan dalam keadaan kritis. Oleh karena itu, perlu ditemukan proses pemurnian air dengan metode yang efisien. Penelitian akan dilakukan di kota Bandung dengan fokus air baku dari sungai yang sudah terkontaminasi dan air sumur yang tidak layak dikonsumsi Air baku tersebut diolah menjadi air bersih dengan proses kimia-fisika. Proses pengolahan air diamati dan dirancang ke dalam rangkaian alat yang sederhana, murah dan mudah dioperasikan. Penelitian dilakukan di 3 titik aliran sungai Cikapundung dan 1 titik di sungai Cisangkuy Banjaran., dari hasil pemeriksaan air di Laboratorium didapat bahwa air baku sungai Cikapundung sampel 1, 1A dan 1C dan air sungai Cisangkuy sampel 1B masih mudah diolah menjadi air bersih dengan sistem pengendapan semalam sambil diberi kaporit dan tawas kemudian dilakukan penyaringan sederhana, Sedangkan untuk syarat air minum ada beberapa unsur yang harus dikurangi, untuk air baku sungai Cikapundung sampel 1 unsur yang tidak memenuhi yaitu, Besi 0,38, Mangan 0,18 gan Timbal 0,0118, untuk sampel $1 \mathrm{~A}$ masih memenuhi syarat air minum, untuk sampel $1 \mathrm{C}$ unsur yang tidak memenuhi yaitu, Besi 0,43 dan Mangan 0,12. Untuk sampel 1B unsur yang tidak memenuhi yaitu, Besi 0,46 dan Mangan 0,33. Untuk air sumur sampel 1D unsur yang tidak memenuhi sebagai air minum pH 6,06 dan Timbal 0,016. Untuk Penyaringan awal dibutuhkan waktu yang cukup signifikan, sehingga tidak meningkatkan parameter-parameter yang tidak diharapkan. Dari hasil penelitian ini dirancang 2 buah alat penyaringan yaitu : Alat penyaringan dengan 1 tabung dan Alat penyaringan dengan 2 tabung.
\end{abstract}

Kata Kunci: pengolahan air, air bersih

\begin{abstract}
Nowadays, clean water becomes scarce and various diseases caused by contaminated raw water affects almost the entire population of the world. Water crisis is estimated to be occurred in Indonesia by 2025. Ground water in Bandung is also stated in critical condition. Therefore, it is necessary to find the water purification process in an efficient method. Research will be conducted in Bandung focusing on well water that is not consumable and raw water from rivers that have been contaminated. Raw water is treated into clean water with chemical-physical processes. Water treatment process are observed and designed into a series of equipment that are simple, inexpensive and easy to operate. The study was conducted at three spot of Cikapundung River and one spot at the Cisangkuy River at Banjaran. Laboratory inspection found that the raw water sample from Cikapundung River (sample 1, 1A and 1C) and from Cisangkuy River (sample 1B) can be easily treated into clean water by overnight chlorine and alum precipitation system and by a simple filtering system. Meanwhile for the requirement of drinking water, there are several elements that must be reduced; on sample 1: Iron 0.38, Manganese 0.18, Lead 0.0118; sample 1A already complete the requirement of drinking water; on sample 1B: Iron 0.43, and Manganese 0.12; on sample 1C: pH 6,06 and Lead 0,016. Initial filtration should be conducted not in a shortterm, because it can increase the unexpected parameters.This research results in the designation of
\end{abstract}


two types of Water Treatment Equipment, which are: single tube water filtration system and double tube water filtration.

Keywords: water treatment, clean water

\section{PENDAHULUAN}

\section{Latar Belakang}

Air merupakan kebutuhan dasar manusia, terutama sebagai air minum. Tingginya modernisasi menyebabkan menurunnya kualitas air. Pada Pekan Lingkungan Indonesia 2009 di Jakarta Convention Centre, 25 Maret 2009, Menteri Lingkungan Hidup, Rachmat Witoelar mengatakan masyarakat dunia tak hanya terancam kelaparan namun juga kehausan. Kelangkaan air paling parah di kawasan Afrika. Sedangkan untuk Asia Tengah adalah Indonesia, khususnya di Jawa dan sepanjang pantai utara. (Fajar Indonesia, 26 Maret 2009).

Data Dinas Pekerjaan Umum menunjukkan sekitar 70 persen populasi Indonesia mengkonsumsi air yang sudah terkontaminasi zat-zat berbahaya. Hampir 100 juta orang Indonesia punya akses terbatas mendapatkan air bersih. Hanya sekitar 4,5 persen penduduk Pulau Jawa, dimana 65 persen penduduk Indonesia tinggal di pulau tersebut, bisa mengkonsumsi air bersih.

Saat ini, pengelolaan sumber daya air di Indonesia masih berorientasi pada sisi penyediaan. Dirjen Sumber Daya Air Departemen PU Basuki Hadimuljono mengatakan "Degradasi air akibat pertambangan, perambahan hutan, eksploitasi air, pencemaran dan peningkatan sedimentasi air di sungai bisa menyebabkan krisis air. Indonesia diperkirakan mengalami krisis air pada 2025." (Westjavawater, 2005)

Setiap tahun kondisi lingkungan hidup cenderung menurun. Selain krisis air, negeri ini juga menjadi langganan bencana alam. Harian Fajar Indonesia (26 Maret 2009) juga mengutip pernyataan Deputi Komunikasi Lingkungan dan Pemberdayaan Manusia Kementerian Lingkungan Hidup, Hendri Bastaman, "Dari 33 propinsi, sekitar 27 propinsi lumayan parah, diantaranya terkena peristiwa longsor dan banjir. Ini yang harus kita carikan solusinya."

Majewski dan Chan, seperti yang dikutip oleh Ewing (2008), menjelaskan bahwa ketersediaan akan air layak minum secara cepat menjadi sebuah masalah sosial-ekonomi di seluruh dunia, terutama di negara berkembang. Teknologi pemurnian air seringkali rumit dan membutuhkan peralatan yang canggih. Selain itu, pemurnian air juga membutuhkan biaya yang mahal dan perawatan yang mahal pula. 


\section{Tujuan}

Berdasarkan latar belakang yang telah dijabarkan sebelumnya, maka penelitian ini dilakukan dengan tujuan untuk mempelajari karakteristik air sungai Cikapundung di Kota Bandung dan mengolah air sungai Cikapundung yang tidak layak dikonsumsi menjadi air bersih.

\section{Fokus Penelitian}

Penelitian dilakukan di Kota Bandung dengan fokus air sungai Cikapundung. Pemilihan sampel dilakukan dengan cara convenience sampling di Sungai Cikapundung.. Mengungkap mutu air sungai Cikapundung yang terdapat di Kota Bandung dan Mempelajari proses pengolahan air yang harus dilakukan untuk mendapatkan air bersih.

\section{Tahapan Penelitian}

Tahapan dari penelitian ini adalah:

1. Observasi dan dokumentasi pada objek penelitian

2. Mengumpulkan data mengenai air sungai Cikapundung

3. Menganalisis proses pengolahan air tidak layak konsumsi menjadi air bersih.

4. Penulisan laporan

\section{Rumusan Masalah}

Tingginya modernisasi di daerah perkotaan, seperti Kota Bandung mengakibatkan kualitas air terus menurun. Pertumbuhan penduduk juga menyebabkan permintaan yang tinggi terhadap air bersih. Pada daerah bencana banjir atau bencana alam lainnya, masyarakat yang terkena musibah membutuhkan air bersih. Oleh karena itu, diperlukan cara penanggulangan untuk memenuhi kebutuhan masyarakat akan air bersih dan air minum.

\section{STUDI PUSTAKA}

\section{Kondisi Air Bersih di Kota Bandung}

Kepala Dinas Pertambangan Provinsi Jawa Barat, H. Ismail Hasjim, mengemukakan bahwa kondisi cekungan Bandung sudah sangat kritis, sehingga pengawasan pengambilan air bawah tanah $(\mathrm{ABT})$ di zona ini akan diperketat. Bahkan untuk tiga wilayah, yakni kawasan Ujungberung, Leuwigajah dan Dayeuhkolot, pemerintah tidak akan lagi mengeluarkan izin pengambilan ABT. 
Sedangkan untuk sumur yang sudah ada, volumenya diperkecil. (Westjavawater, 2005)

Wakil Gubernur Jabar, Nu'man A. Hakim saat membuka Rapat Koordinasi Bidang Pertambangan se-Jabar mengungkapkan bahwa air bawah tanah khususnya di cekungan Bandung harus dikendalikan. Nu'man menekankan masalah ABT cekungan Bandung benar-benar harus ditangani serus. "Kami sempat dipanggil oleh Komisi VIII DPR RI menanyakan keseriusan penanganan air bawah tanah cekungan Bandung. Apabila kondisi ABT dibiarkan terus kritis, tidak akan lama lagi ABT akan habis dan selanjutnya Bandung akan kekurangan air yang hebat," katanya. (Westjavawater, 2005)

\section{Pentingnya Pengolahan Air Bersih}

Organisasi kesehatan dunia, WHO (The World Health Organization) menerbitkan panduan kualitas air bersih. Panduan ini memberi dasar untuk membantu negara-negara yang ada menciptakan standar air bersih, peraturan dan norma yang sesuai dengan keadaan negara tersebut dan keadaan di sekitarnya. Pemerintah Republik Indonesia juga telah mengeluarkan Peraturan Pemerintah Nomor 82 tahun 2001 tentang pengelolaan kualitas air dan pengendalian pencemaran air.

Mr. Bob MacMullan, sekretaris parlemen untuk bantuan pengembangan internasional AUSAID, menyatakan bahwa sanitasi yang baik dan air layak minum adalah sangat penting untuk meningkatkan kesehatan dan hasil pendidikan bagi masyarakat miskin, terutama wanita, anak-anak, dan orang cacat. Kita harus meningkatkan usaha untuk membantu mengurangi proporsi masyarakat yang tidak memiliki akses pada air layak minum dan sanitasi. Hal ini sesuai dengan tujuan pengembangan millennium PBB yang ingin dicapai pada tahun 2015 (AUSAID, 2009).

IBM (2009) juga mengadakan proyek penelitian untuk mendapatkan air bersih. Bob Allen, manajer proyek pemurnian air IBM, menyatakan bahwa saat ini air bersih menjadi langka dan penyakit yang disebabkan oleh air kotor mempengaruhi hampir seluruh penduduk dunia. Oleh karena itu kita harus berpacu untuk menemukan metode yang efisien untuk memurnikan sumber daya 
alam ini. IBM saat ini tengah meneliti proses pengolahan air dengan menggunakan teknologi penyaringan membran.

AUSAID pada Sanitation and Water Conference yang diadakan di Melbourne Oktober 2008, melaporkan lebih dari 880 juta penduduk dunia yang tidak memiliki akses pada air bersih. Di daerah perkotaan di Indonesia, air minum yang memiliki kualitas baik hanya 68\% (Anwar, 2004). Menurut studi yang dilakukan oleh Dep. Kimpraswil tahun 2003, seperti yang dikutip oleh Anwar (2004), penduduk yang memiliki akses terhadap air ledeng hanya 39\% dari total penduduk perkotaan atau sekitar 33 juta jiwa.

Ewing (2008) mengutip laporan UNESCO yang berjudul "Water for People - Water for Life”. Dalam laporan tersebut dinyatakan lebih dari 6000 orang meninggal setiap harinya akibat penyakit yang disebabkan oleh air, termasuk diare, infeksi cacing, dan penyakit infeksi lainnya. Polutan organik yang berasal dari limbah industri dari pengolahan kertas dan pulp, pabrik tekstil dan kulit, penempaan baja dan pemurnian petrokimia merupakan penyebab utama. Proses pemurnian air dapat membantu mencegah penyakit dan racun yang mengancam jutaan orang.

Menurunnya kualitas air minum dapat menimbulkan berbagai masalah. Kontaminasi mikroba di dalam air minum dapat menimbulkan berbagai penyakit. Oleh karena itu, pengendalian penyakit yang disebabkan oleh air minum merupakan hal yang penting diperhatikan oleh pengelola air minum (LeChevallier dan $\mathrm{Au}, 2004)$.

Sebuah studi yang diterbitkan dalam International Journal of Cancer pada bulan April 2006 mengemukakan hubungan yang signifikan antara konsumsi air yang mengandung klorin dengan kanker saluran kencing pada pria. McMahon juga mengutip dari The National Cancer Institute yang memperkirakan resiko terkena kanker lebih besar 93\% pada orang yang mengkonsumsi air yang mengandung klorin. Oleh karena itu proses pemurnian air sangat penting untuk dilakukan. WHO juga membuktikan pada suatu negara yang penduduknya mengkonsumsi air yang terkontaminasi arsenik dalam jangka waktu lama, satu dari sepuluh orang yang meminum air tersebut meninggal akibat kanker yang 
disebabkan oleh senyawa arsenik, termasuk kanker paru-paru, saluran kencing, dan kulit.

Pada Tabel 2.1 dijelaskan kontaminasi air dari gas sampai dengan padatan, dampak yang terjadi serta bagaimana proses pemurnian dapat dilakukan juga secara umum bahan dasar air ditemukan. Proses pengolahan yang terbaik harus dipilih untuk memastikan produksi air bersih yang bermutu tinggi. Hal-hal yang harus diperhatikan dalam pengolahan air bersih antara lain: kualitas air baku, perkiraan konsentrasi bakteri patogen dalam air, pengujian kesesuaian hasil pengolahan air dengan target yang ingin dicapai, dan pemilihan alat ukur untuk mengendalikan operasi pengolahan air (LeChevallier dan Au, 2004).

Tabel 2.1. Kontaminan dalam Air (Enercon Consultancy Services, 2003).

\begin{tabular}{|c|c|c|c|}
\hline Pengotor & Dampak & Proses Pemurnian & Keterangan \\
\hline \multicolumn{4}{|l|}{ Gas Terlarut } \\
\hline $\begin{array}{l}\text { Hidrogen } \\
\text { Sulfida }\left(\mathrm{H}_{2} \mathrm{~S}\right)\end{array}$ & $\begin{array}{l}\text { Bau tak sedap, } \\
\text { rasa tidak enak, } \\
\text { dan korosif terhadap } \\
\text { logam }\end{array}$ & $\begin{array}{l}\text { Aerasi, } \\
\text { Filtrasi, } \\
\text { Klorinasi }\end{array}$ & $\begin{array}{l}\text { Ditemukan pada } \\
\text { air bawah tanah, } \\
\text { atau aliran air limbah }\end{array}$ \\
\hline $\begin{array}{l}\text { Karbon } \\
\text { Dioksida } \\
\left(\mathrm{CO}_{2}\right)\end{array}$ & $\begin{array}{l}\text { Korosif, membentuk } \\
\text { asam karbonat }\end{array}$ & $\begin{array}{l}\text { Deaerasi, } \\
\text { Netralisasi } \\
\text { dengan alkali }\end{array}$ & \\
\hline $\begin{array}{l}\text { Oksigen } \\
\left(\mathrm{O}_{2}\right)\end{array}$ & $\begin{array}{l}\text { Korosi dan } \\
\text { pemngan pipa }\end{array}$ & $\begin{array}{l}\text { Deaerasi dan } \\
\text { perlakuan kimia } \\
\text { menggunakan } \\
\text { sodium sulfit } \\
\text { atau Hydrazin }\end{array}$ & \\
\hline \multicolumn{4}{|l|}{ Padatan } \\
\hline Lumpur & Endapan dan kerak & Klarifikasi dan filtrasi & $\begin{array}{l}\text { Batas maksimum } \\
5 \text { ppm untuk } \\
\text { pemakaian umum, } \\
\text { dan } 10 \text { ppm untuk } \\
\text { air minum }\end{array}$ \\
\hline $\begin{array}{l}\text { Zat organik } \\
\text { (senyawa } \\
\text { diatomik, } \\
\text { jamur, } \\
\text { bakteri } \\
\text { dari kotoran, } \\
\text { bakteri besi } \\
\text { /mangan) }\end{array}$ & $\begin{array}{l}\text { Busa, endapan, } \\
\text { pemampatan pipa } \\
\text { dan korosi }\end{array}$ & $\begin{array}{l}\text { Klarifikasi, filtrasi } \\
\text { dan perlakuan kimia }\end{array}$ & $\begin{array}{l}\text { Ditemukan pada air } \\
\text { permukaan akibat } \\
\text { pembusukan tanaman } \\
\text { dan limbah pertanian. } \\
\text { Senyawea organic } \\
\text { terurai menjadi asam } \\
\text { dan } \\
\text { mengakibatkan } \\
\text { pH air menjadi rendah }\end{array}$ \\
\hline \multicolumn{4}{|c|}{ Padatan koloid terlarut } \\
\hline Minyak & Busa, endapan & Koagulasi dan filtrasi & \\
\hline $\begin{array}{l}\text { Kesadahan: } \\
\text { kalsium }(\mathrm{Ca}) \\
\text { dan magnesium } \\
(\mathrm{Mg})\end{array}$ & Kerak, isolator panas & Pelunakan air & $\begin{array}{l}\text { Berbentuk senyawa } \\
\text { bikarbonat, sulfat, } \\
\text { dan nitrat. }\end{array}$ \\
\hline
\end{tabular}




\begin{tabular}{|c|c|c|c|}
\hline \multicolumn{4}{|c|}{ Tabel 2.1 lanjutan. } \\
\hline $\begin{array}{l}\text { Alkalinitas } \\
\text { (NaOH, } \\
\mathrm{NaHCO}_{3} \text {, } \\
\mathrm{Na}_{2} \mathrm{CO}_{3} \text { ) }\end{array}$ & $\begin{array}{l}\text { Busa, asam karbonat } \\
\text { dapat menyebabkan korosi }\end{array}$ & $\begin{array}{l}\text { Deaerasi, } \\
\text { pertukaran ion, } \\
\text { deionisasi, dan } \\
\text { perlakuan asam }\end{array}$ & $\begin{array}{l}\text { Garam sodium }(\mathrm{Na}) \\
\text { selalu ditemukan } \\
\text { dalam air, sangat } \\
\text { mudah larut dan } \\
\text { tidak dapat } \\
\text { dihilangkan dengan } \\
\text { pengendapan kimiawi }\end{array}$ \\
\hline Sulfat $\left(\mathrm{SO}_{4}\right)$ & Kerak & Deionisasi & $\begin{array}{l}\text { Sodium sulfat banyak } \\
\text { ditemukan dalam air, } \\
\text { terutama air dimana } \\
\text { terjadi pengendapan } \\
\text { kalsium dan } \\
\text { magnesium dengan } \\
\text { soda abu } \\
\end{array}$ \\
\hline Klorin (Cl) & Gangguan kesehatan & & \\
\hline $\begin{array}{l}\text { Besi (Fe) } \\
\text { dan } \\
\text { Mangan } \\
(\mathrm{Mn})\end{array}$ & Endapan pada pipa & $\begin{array}{l}\text { Aerasi, filtrasi, } \\
\text { pertukaran ion }\end{array}$ & $\begin{array}{l}\text { Bentuk umum: } \\
\text { besi bikarbonat }\end{array}$ \\
\hline Silika (Si) & $\begin{array}{l}\text { Kerak dan endapan } \\
\text { pada pipa }\end{array}$ & $\begin{array}{l}\text { Deionisasi, } \\
\text { proses soda kapur, } \\
\text { proses kapur-zeolit }\end{array}$ & \\
\hline
\end{tabular}

\section{Proses Pengolahan Air menjadi Air Siap Minum}

Sistem pengolahan air bersih dengan sumber air baku sungai, tanah dan air pegunungan, dengan skala atau standar air minum, memerlukan beberapa proses. Proses yang perlu diterapkan tergantung dari kualitas air baku tersebut. Secara umum proses pengolahan air kotor menjadi air bersih adalah melalui tahapan: penyaringan kasar, deaerasi, pengendapan, pelunakan, dan penyaringan membrane (LeChevallier dan Au, 2004).

\section{Penyaringan Kasar (Roughing Filter)}

Tahap penyaringan kasar ini bertujuan untuk menghilangkan lumpur, ganggang, turbiditas air, virus dan protozoa. Perlakuan awal dilakukan pada bak penampungan air. Aliran air pada tahap penyaringan kasar dilakukan secara upflow, yaitu air dialirkan dari bagian bawah saringan. Aliran upflow bertujuan menghindari pemampatan karena lumpur pada saringan dan untuk mempermudah pembuangan endapan. Media penyaring yang digunakan adalah pasir aktif, dapat dilihat pada Gambar 2.1. 


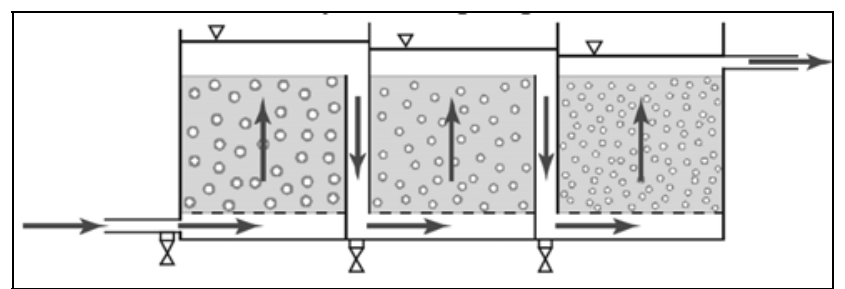

Gambar 2.1. Penyaringan Kasar dengan Aliran Upflow

\section{Deaerasi}

Gas-gas yang terlarut dalam air dapat dihilangkan dengan proses deaerasi. Proses deaerasi berdasarkan Hukum Henry yang menyatakan bahwa kelarutan gas di dalam larutan akan berkurang seiring dengan berkurangnya tekanan parsial gas di atas permukaan larutan. Kelarutan gas juga dipengaruhi oleh temperatur. Jika temperature meningkat maka kelarutan gas akan berkurang.

Gas oksigen yang terdapat dalam air juga dapat merugikan dalam dunia industry. Gas oksigen terlarut dalam air dapat mengakibatkan korosi pada alat-alat yang digunakan. Proses deoksigenasi dilakukan dengan menambahkan zat sodium sulfit $\left(\mathrm{Na}_{2} \mathrm{SO}_{3}\right)$ yang akan menangkap gas O2. Selain itu, dapat juga ditambahkan hidrazin hidrat $\left(\mathrm{N}_{2} \mathrm{H}_{4} \cdot \mathrm{H}_{2} \mathrm{O}\right)$ yang dapat menangkap oksigen, sekaligus mereduksi zat besi oksida atau tembaga oksida yang merupakan hasil korosi.

\section{Pengendapan}

Proses pengendapan atau koagulasi bisa dilakukan dengan menggunakan bahan kimia seperti bahan koagulan (Hipoklorite/PAC). Penambahan oksidator kuat seperti klorin, klorin dioksida atau ozon dapat berfungsi sebagai disinfektan, menonaktifkan sel mikroba karena klorin menyebabkan kerusakan fisik pada membran sel bakteri.

Zat oksidan dapat ditambahkan ke dalam air untuk menghilangkan rasa dan bau, menghilangkan kadar besi dan mangan, dan penghilangan partikelpartikel lain. Hal penting yang harus diperhatikan dalam efisiensi desinfektan adalah konsentrasi, waktu kontak, temperatur, dan pH. Sinar ultraviolet (UV) juga dapat membunuh mikroba melalui reaksi dengan inti sel mikroba dan sangat efektif untuk menghilangkan Cryptosporodium. Untuk mengetahui banyaknya bakteri dalam air, digunakan pelat agar TTC. Pelat agar TTC dicelupkan ke dalam 
air kemudian diletakkan dalam inkubator dengan suhu $27-30^{\circ} \mathrm{C}$ selama $24-48$ jam. Jumlah bakteri yang tumbuh pada medium dibandingkan dengan gambar standar pertumbuhan bakteri. Hal yang perlu diperhatikan adalah keragaman dalam proses dan pengukuran untuk menentukan efektifitas total untuk pengendalian mikroba. Alat-alat ukur tersebut akan memastikan apakah mutu mikroba dalam air yang telah diolah telah memenuhi standar air minum.

\section{Pelunakan air}

Pelunakan air yang mengandung bikarbonat $\mathrm{Ca}\left(\mathrm{HCO}_{3}\right)_{2}$ dan $\mathrm{Mg}\left(\mathrm{HCO}_{3}\right)_{2}$ dapat dilakukan dengan proses kapur. Reaksi yang terjadi adalah sebagai berikut:

$$
\begin{gathered}
\mathrm{Ca}^{2+} \\
\mathrm{HCO}_{3}{ }^{-}+\mathrm{OH} \longrightarrow \mathrm{H}_{2} \mathrm{O}^{-} \mathrm{CO}_{3}{ }^{2-} \longrightarrow \mathrm{CaCO}_{3} \text { precipitates } \\
\left.\mathrm{Mg}^{2+}+2 \mathrm{OH}^{-} \longrightarrow \mathrm{Mg}^{-} \mathrm{OH}\right)_{2} \text { precipitates }
\end{gathered}
$$

Proses ini kemudian dilanjutkan dengan proses zeolit. Zeolit merupakan sodium aluminium silikat hidrat. Air yang mengandung kalsium (Ca) atau magnesium (Mg) jika dilewatkan pada unggun zeolit akan mengalami pertukaran ion. Sodium yang berikatan dengan zeolit akan digantikan oleh kalsium dan magnesium. Zeolit yang sudah jenuh dapat diregenerasi kembali dengan menggunakan garam industri. Pengujian kesadahan air dapat dilakukan dengan cara titrasi menggunakan EDTA (Ethylenediaminetetraacetic Acid), dengan indikator EBT (Eriochrome Black T). Titrasi dilakukan untuk menganalisa banyaknya ion logam di dalam air sampel yang telah diproses. Titik akhir titrasi mudah diamati yaitu perubahan warna dari merah (kompleks logam-EBT) menjadi biru (EBT bebas).

\section{Penyaringan Membran}

Proses penghilangan bakteri dari dalam air minum yang terakhir adalah filtrasi (penyaringan). Dalam proses penyaringan, mikroba dihilangkan dengan kombinasi dari perlakuan fisika-hidrodinamika dengan larutan kimia. Penyaringan 
pasir lambat dapat mengurangi jumlah mikroba melalu interaksi biologis dan fisika-kimia. Penyaringan membran juga dapat dilakukan untuk menghilangkan mikroba berdasarkan ukurannya. Penyaringan membran sangat efektif untuk meghilangkan mikroba yang lebih besar daripada ukutan pori-pori membran. Seluruh proses pengolahan air ini dapat menghilangkan patogen hingga 4 log atau lebih. Penyaringan membran dilakukan dengan menggunakan metode "reverse osmosis” dengan menggunakan media penyaring cellulose acetate, poliamida, atau polipropilen.

\section{Pengujian pH}

Skala pH menyatakan konsentrasi dari ion hidrogen yang bermuatan positif $\left(\mathrm{H}^{+}\right)$yang dinyatakan dalam bentuk logaritma. $\mathrm{pH}$ dinyatakan dalam rentang $0-14$. Semakin rendah $\mathrm{pH}$ menyatakan semakin banyak ion hidogen $\left(\mathrm{H}^{+}\right)$ atau tingkat keasaman yang semakin tinggi. Sebaliknya, semakin tinggi $\mathrm{pH}$ maka semakin banyak ion hidroksida $\left(\mathrm{OH}^{-}\right)$atau tingkat alkalinitas semakin tinggi. $\mathrm{pH}=$ 7 menyatakan titik tengah atau netral, dimana jumlah ion hydrogen sama dengan ion hidroksida. Pengujian $\mathrm{pH}$ dapat dilakukan dengan elektrometrik dan kolorimetrik. Metode elektrometrik dilakukan dengan menggunakan $\mathrm{pH}$ meter dengan cara mengalirkan arus listrik. Metode ini memberikan hasil yang lebih akurat. Metode kolorimetrik dilakukan dengan penambahan zat warna, yang warnanya akan berubah sesuai dengan pH-nya. Kemudian warna yang terjadi dibandingkan secara visual dengan standar.

\section{METODE PENELITIAN}

Team peneliti menggunakan metode deskriptif kuantitatif dalam mengevaluasi kadar kontaminan dalam air sungai yang tidak layak dikonsumsi. Peneliti melakukan perancangan alat pengolahan air sungai yang tidak layak dikonsumsi dan kotor menjadi air bersih. Peneliti melakukan observasi terhadap kinerja alat pengolahan air yang akan dibuat. Air yang telah diolah kemudian diuji kualitasnya. Gambar 3.1 menjelaskan proses pengolahan air yang dilakukan. 


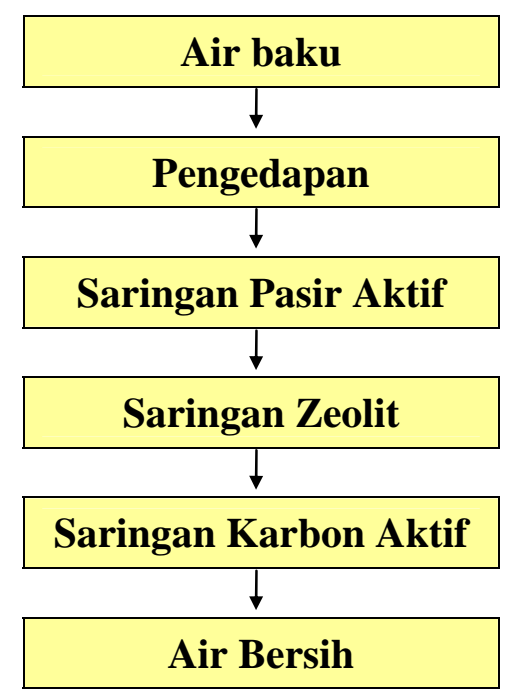

Gambar 3.1. Diagram alir proses pengolahan air

Penelitian Dilakukan Dalam Tiga Tahapan, yaitu Percobaan penyaringan air, Evaluasi hasil percobaan, dan Perancangan alat. Tahap pertama dilakukan mulai tanggal 16 Mei 2010 hingga 21 Juli 2010. Diagram alir percobaan penyaringan air disajikan dalam Gambar 3.2.

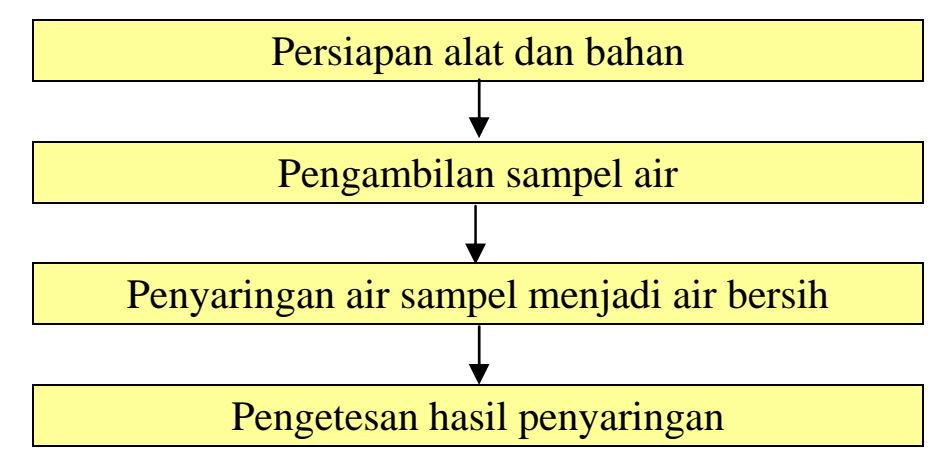

Gambar 3.2. Diagram alir percobaan penyaringan air

Alat penyaringan air disiapkan sesuai dengan skema dalam Gambar 3.3. Air sampel akan ditampung terlebih dahulu di dalam bak pengendapan. Setelah itu air dialirkan melewati media penyaringan pasir aktif, mangan zeolit, dan karbon aktif. 


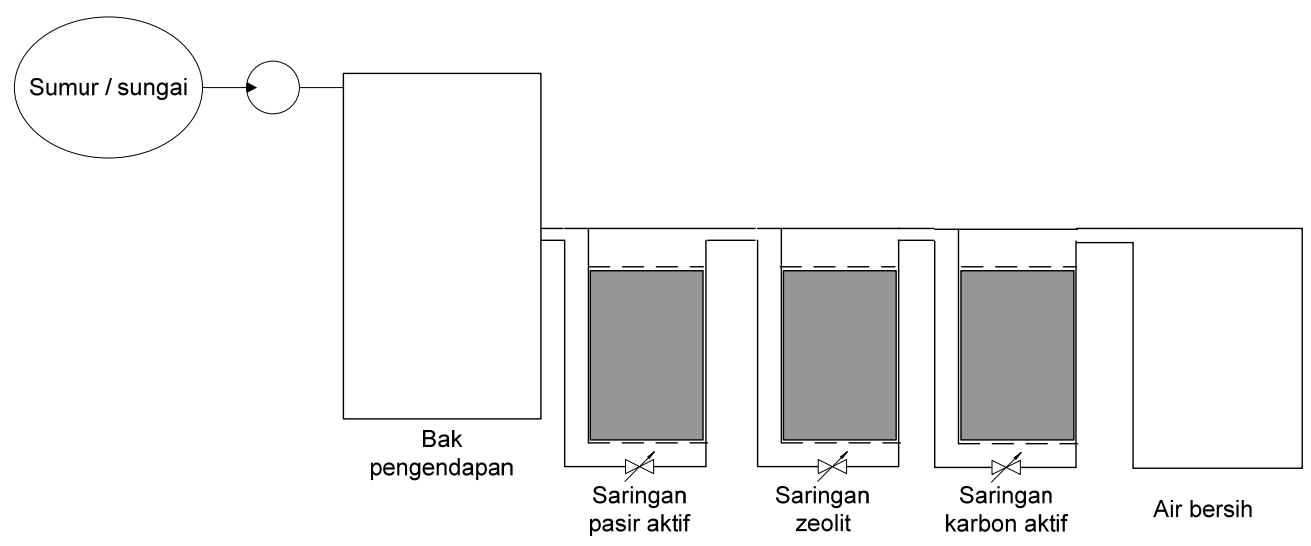

Gambar 3.3. Diagram Alir Proses Penyaringan Air

\section{Alat-alat yang disiapkan meliputi:}

1. Bak pengendapan berupa toren berukuran $500 \mathrm{~cm}^{3}$.

2. Tiga buah kolom penyaringan yang terbuat dari kaca berukuran $30 \mathrm{~cm} \times 30 \mathrm{~cm} \times 50 \mathrm{~cm}$, dengan tebal kaca $5 \mathrm{~mm}$.

3. Media penyaringan, yaitu: Pasir Aktif, Mangan Zeolit/zeolit, Karbon Aktif.

4. Stop kran, pipa, dan selang penghubung antar bak dan media penyaringan.

5. Jerigen penampungan air bersih untuk pengujian Laboratorium.

Air sampel yang digunakan dalam percobaan ini adalah air sungai Cikapundung beserta anak sungainya yang terdapat di kota Bandung. Data air sampel disajikan pada Tabel 3.1.

Tabel 3.1. Data Air Sampel Sungai Cikapundung

\begin{tabular}{|c|l|c|c|}
\hline Sampel & Lokasi pengambilan air & $\begin{array}{c}\text { Tanggal } \\
\text { pengambilan } \\
\text { sampel }\end{array}$ & $\begin{array}{c}\text { Tanggal } \\
\text { percobaan \& } \\
\text { pengetesan }\end{array}$ \\
\hline 1 & Jalan Siliwangi & 16 Mei 2010 & 20 Mei 2010 \\
& & 22 Mei 2010 \\
\hline 1A & Jalan Pasirluyu & 27 Mei 2010 & 27 Mei 2010 \\
\hline 1C & Jalan Buah Batu (dekat pintu tol & 7 Juni 2010 & 29 Juni 2010 \\
& Buah Batu) & & 1 Juli 2010 \\
& & & 21 Juli 2010 \\
\hline
\end{tabular}



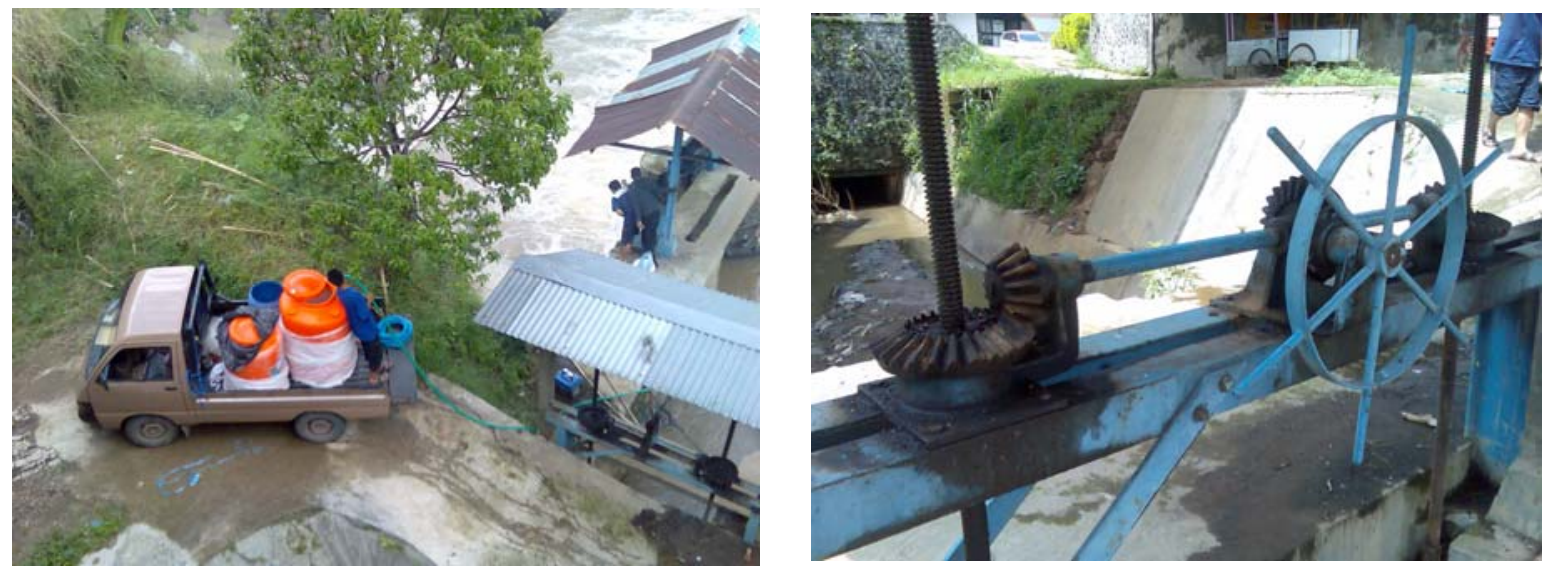

Gambar 3.4. Lokasi Pengambilan Sampel 1 (16 Mei 2010)
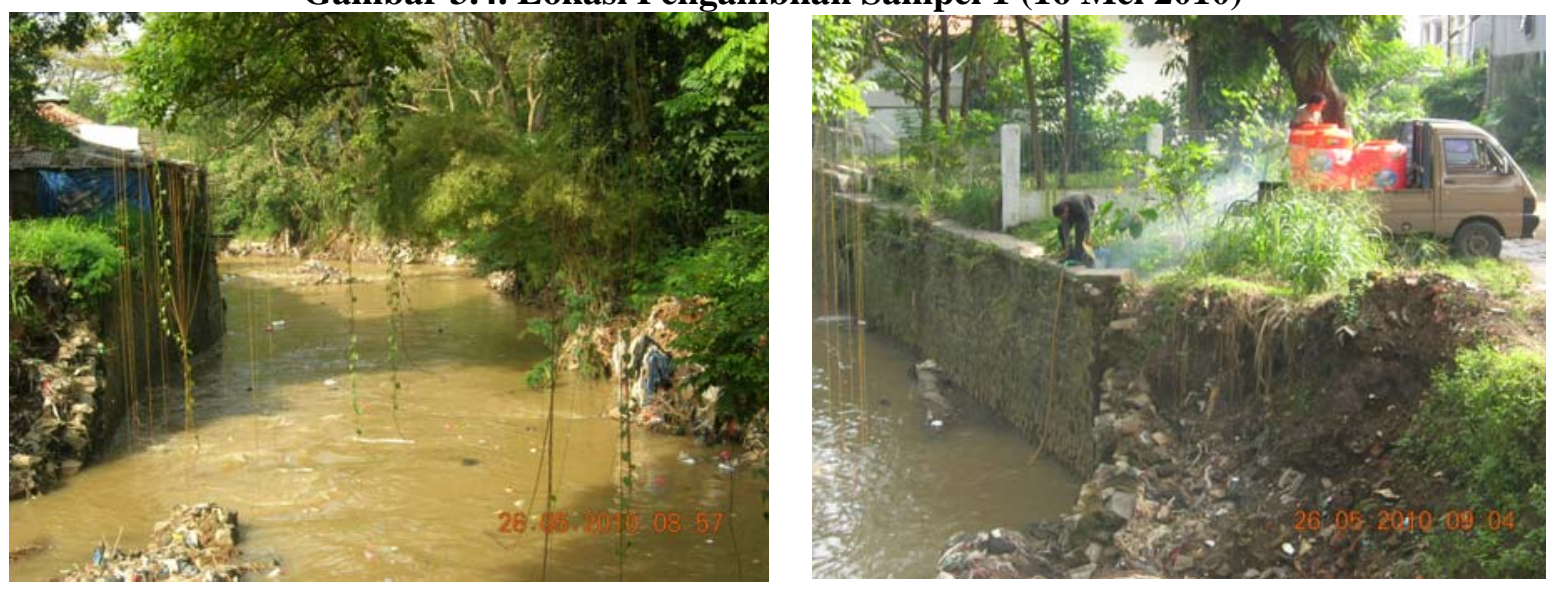

Gambar 3.5. Lokasi Pengambilan Sampel 2 (28 Mei 2010)
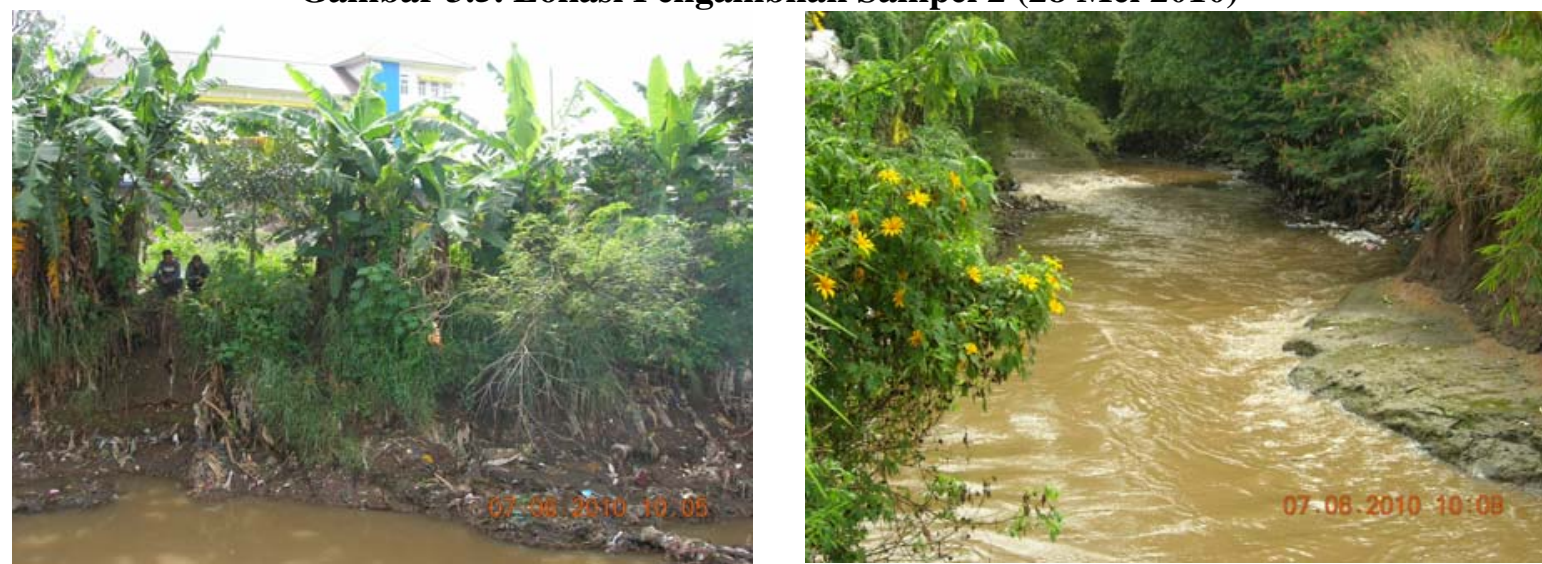

Gambar 3.6. Lokasi Pengambilan Sampel 1C ( 7 Juni 2010)

Air sampel ditampung ke dalam bak pengendapan dengan ditambahkan kaporit dan tawas. Kaporit yang ditambahkan adalah 1/4 tablet ke dalam 500 cm3 air. Fungsi kaporit adalah sebagai desinfektan. Tawas yang ditambahkan adalah 50 gram ke dalam $500 \mathrm{~cm} 3$ air. Fungsi tawas adalah sebagai koagulan, untuk mengendapkan partikel-partikel pengotor dalam air. Kemudian air sampel 
diendapkan selama 1 malam. Air sampel kemudian dialirkan melalui media penyaringan dengan menggunakan gaya gravitasi. Rangkaian media penyaringan air ditunjukkan dalam Gambar 3.7. Urutan media penyaringan air yang digunakan adalah pasir aktif - mangan zeolit - karbon aktif.

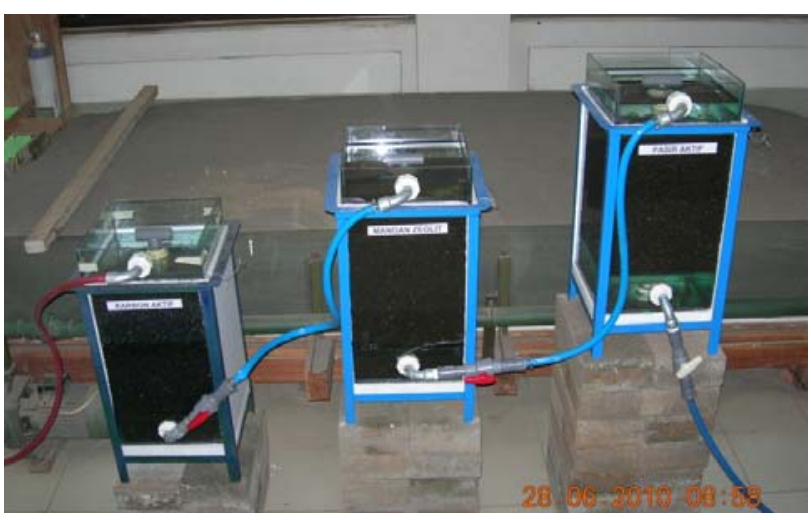

Gambar 3.7. Rangkaian Media Penyaringan Air

Air bersih yang merupakan keluaran dari rangkaian media saring tersebut kemudian dianalisa kualitasnya di Laboratorium Kesehatan Masyarakat SETIABUDI. Hasil analisa air disajikan pada Tabel 3.2. Baku mutu mengacu pada persyaratan air bersih No. 416/MENKES/PE/IX/90. Dan hasil percobaan dapat dilihat pada Tabel 3.2. Hasil dari analisis kualitas air dapat dilihat pada Tabel 3.3. Jika dalam bentuk grafik dapat dilihat pada Gambar 3.4 - Gambar 3.6.

Tabel 3.2. Keterangan hasil percobaan

\begin{tabular}{|c|c|}
\hline 1 & : Air baku Sungai Cikapundung di Jalan S Siliwangi \\
\hline 5 & : Air sampel 1 yang telah melewati 3 kolom penyaringan \\
\hline 6 & : $\mid$ Air sampel 1 yang telah melewati saringan tabung I dia $3 " \mathrm{t} 70 \mathrm{~cm}$ \\
\hline 10 & : Air sampel 1 yang telah melewati saringan tabung II DIA $4 " \mathrm{t} 95 \mathrm{~cm}$ \\
\hline $1 \mathrm{~A}$ & : Air baku Sungai Cikapundung di Jalan Pasirluyu \\
\hline $5 \mathrm{~A}$ & : Air sampel $1 \mathrm{~A}$ yang telah melewati 3 kolom penyaringan \\
\hline $6 \mathrm{~A}$ & : $\mid$ Air sampel 1A yang telah melewati saringan tabung $\mathrm{II}$ dia $4 " \mathrm{t} 95 \mathrm{~cm}$ \\
\hline $1 \mathrm{~A}$ & : Air baku S ungai Cikapundung di Jalan Pasirluyu \\
\hline $8 \mathrm{~B}$ & : Air sampel 1B yang telah melewati 3 kolom penyaringan \\
\hline $9 \mathrm{~B}$ & : Air sampel 1A yang telah melewati saringan tabung 11 dia $4 " \mathrm{t} 95 \mathrm{~cm}$ \\
\hline $1 \mathrm{C}$ & : Air baku Sungai Cikapundung di Jalan Buah Batu \\
\hline $5 \mathrm{C}$ & : Air sampel $1 \mathrm{C}$ yang telah melewati 3 kolom penyaringan \\
\hline $6 \mathrm{C}$ & : $\mid$ Air sampel 1C yang telah melewati saringan tabung II dia 4 " t $95 \mathrm{~cm}$ \\
\hline $7 C$ & : Air sampel 1C yang telah melewati saringan tabung II (mangan zeolit) dia 4 " t $95 \mathrm{~cm}$ \\
\hline $8 \mathrm{C}$ & : Air sampel $1 \mathrm{C}$ yang telah melewati saringan tabung II (zeolit) dia 4 " t $95 \mathrm{~cm}$ \\
\hline $9 \mathrm{C}$ & : Air sampel $1 \mathrm{C}$ yang telah melewati 3 kolom penyaringan, aliran air downflow \\
\hline
\end{tabular}




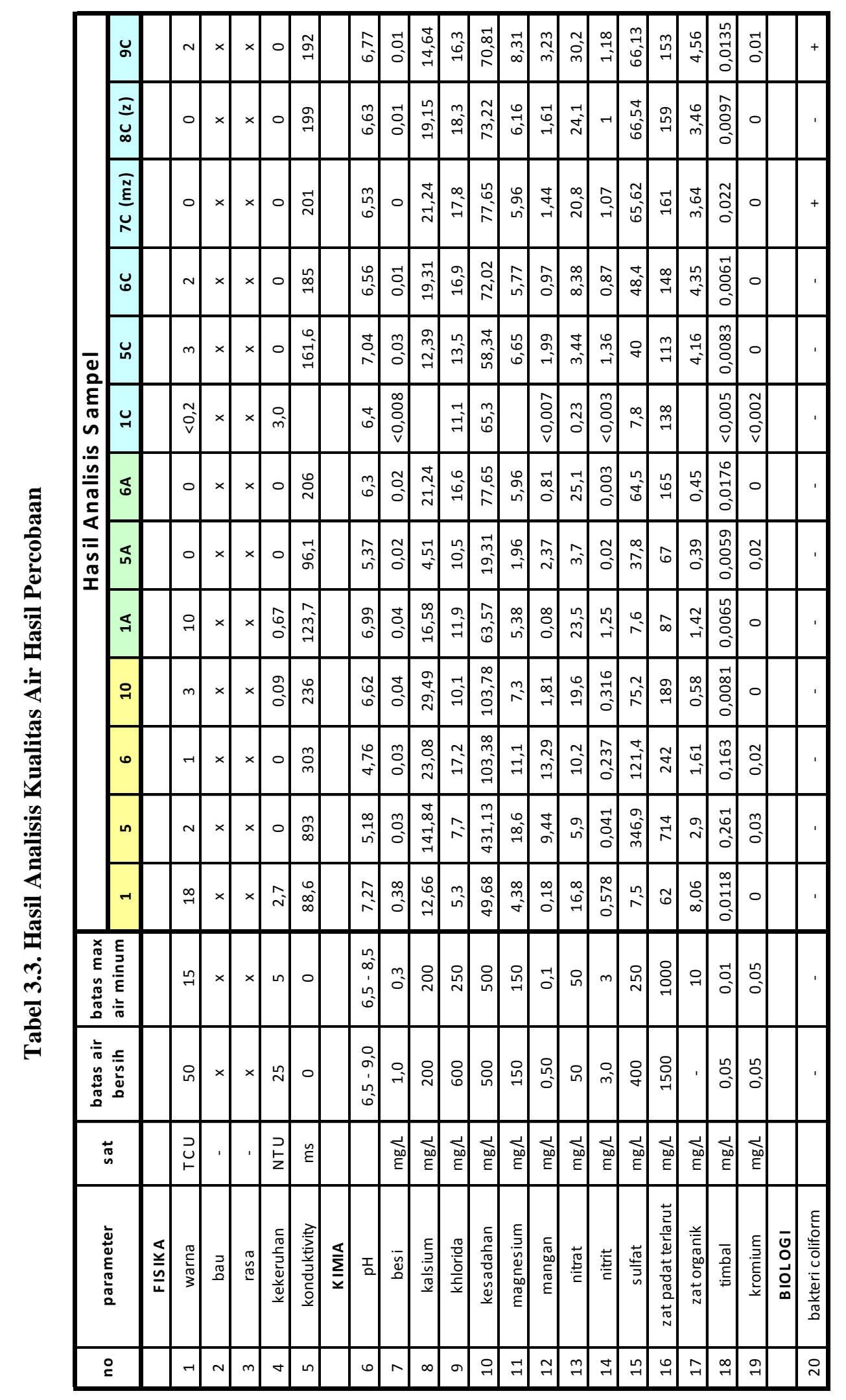



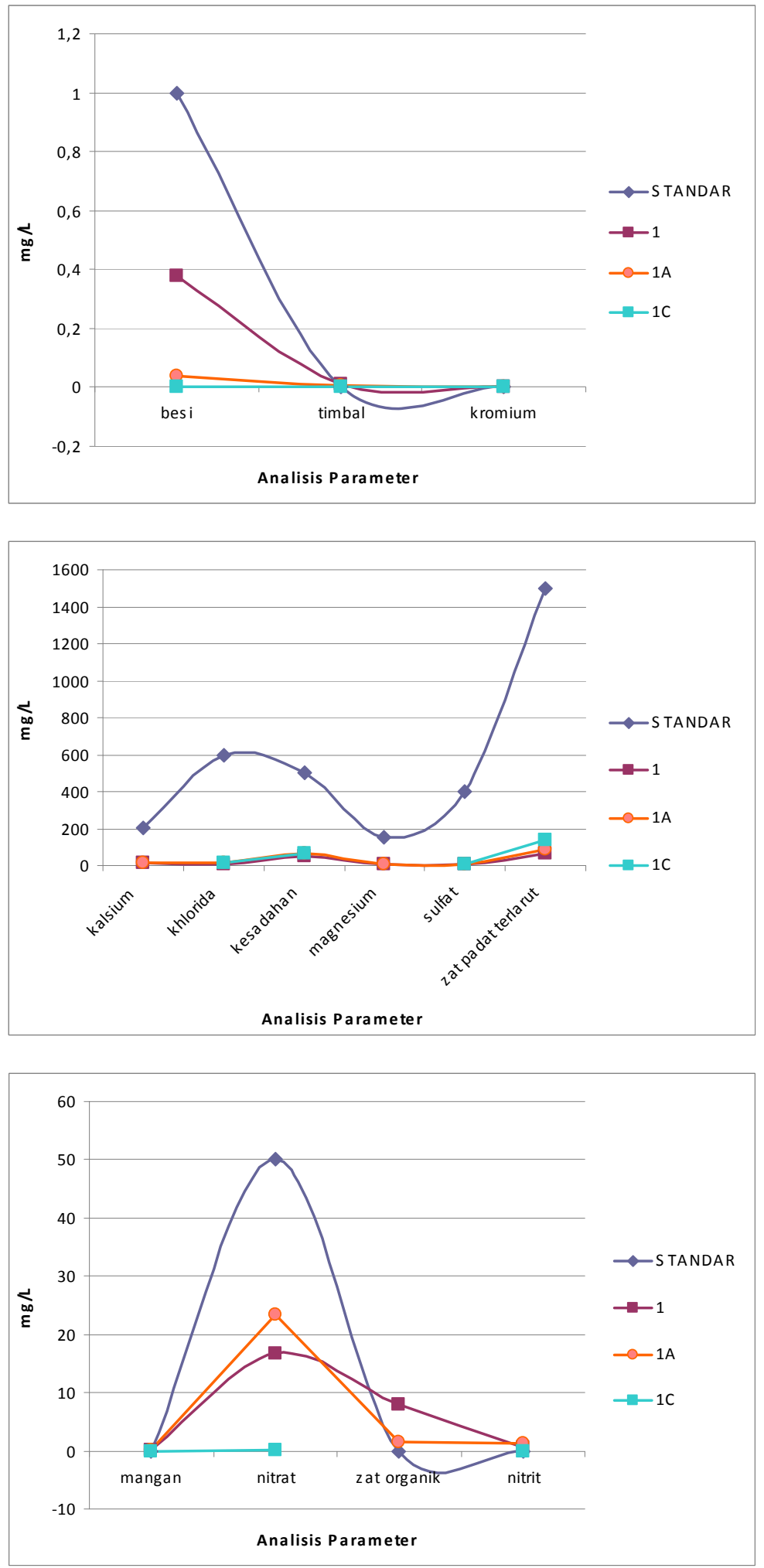

Gambar 3.8. Hasil pengujian kualitas air baku Sungai Cikapundung. 

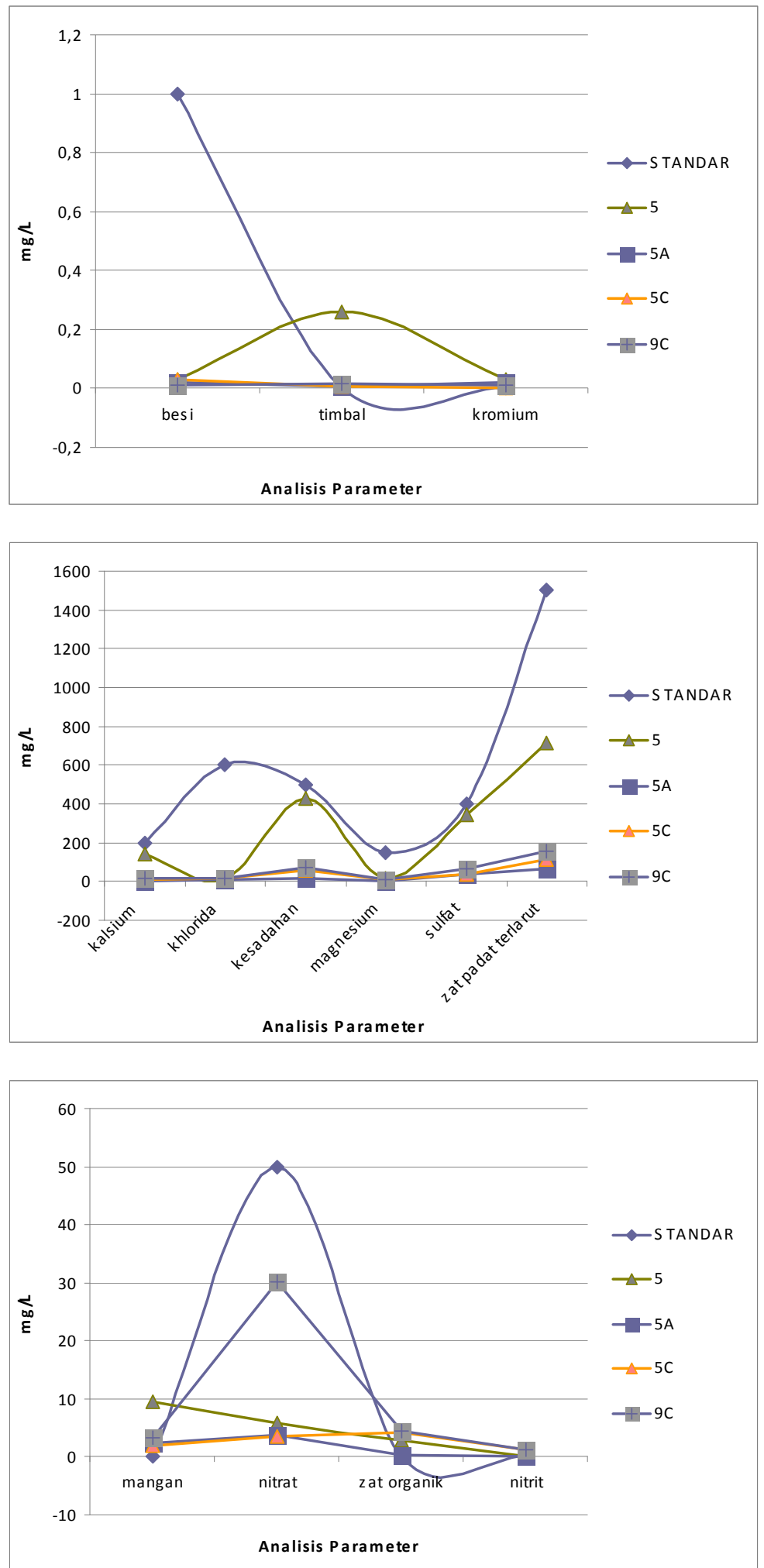

Gambar 3.9. Hasil pengujian air yang telah melewati tiga kolom penyaringan. 

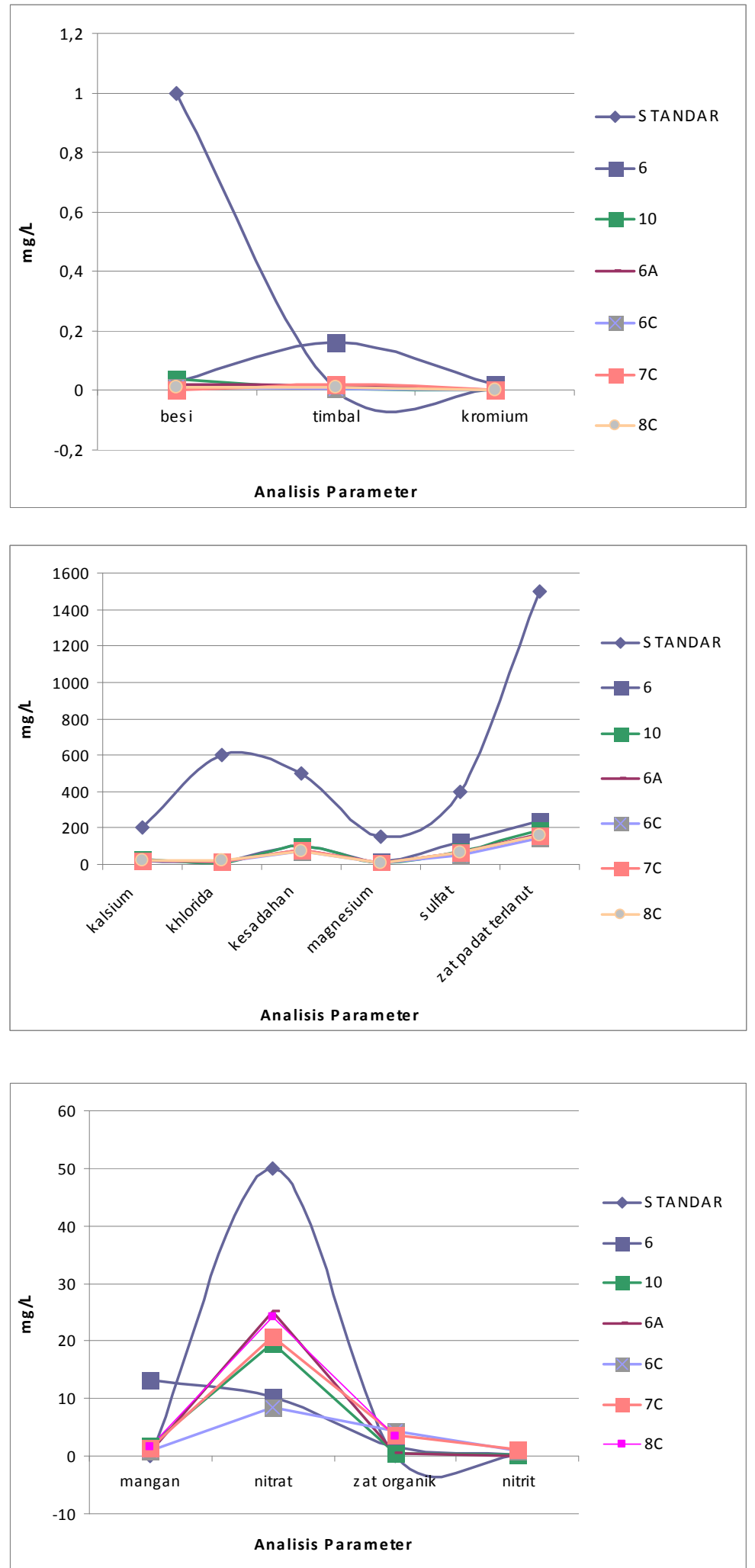

Gambar 3.10. Hasil pengujian air yang melewati media penyaringan tabung 


\section{KESIMPULAN}

Berdasarkan hasil pemeriksaan air di-Laboratorium Kesehatan Masyarakat “SETIA BUDI “, maka dapat diambil kesimpulan sebagai berikut:

1. Air baku dari sungai Cikapundung masih belum terlalu terkontaminasi, dan dengan pengolahan air yang sederhana dengan campuran Pasir Aktif : Karbon Aktif : Mangan Zeolit / zeolit dengan perbandingan 6 : 2,5 : 1,5 dapat dihasikan air bersih yang layak digunakan.

2. Hasil percobaan menunjukkan peningkatan beberapa parameter dari air baku, karena penyaringannya kurang lama dikarenakan terbatasnya penyediaan air baku dalam peroses penyaringan.

3. Hasil penyaringan air melalui kolam penyaringan maupun tabung menghasilkan air yang jernih dan tidak berbau.

4. Jika mau digunakan sebagai air minum sebaiknya dilakukan proses pendidihan terlebih dahulu.

\section{UCAPAN TERIMA KASIH}

Penelitian ini dibiayai oleh Direktorat Jendral Pendidikan Tinggi, Departemen Pendidikan Nasional dalam Hibah Penelitian Dosen Tahun 2010, dengan judul "Perancangan Alat Pengolahan Air Yang Ramah Lingkungan, Sederhana, Murah Dan Mudah Dioperasikan”.

\section{DAFTAR PUSTAKA}

1. Anwar, Alizar (2004). "Pelayanan Air Minum Wilayah Perkotaan di Indonesia". Journalist Workshop on Water Issues.

2. Bob Ewing (2008). "Nanotechnology Used to Clean Water". http://www.digitaljournal.com/article/250604/Nanotechnology_Used_to_Clean_ Water

3. Enercon Consultancy Services (2003). Boiler feed-Water Treatment.

4. Fajar Indonesia (26 Maret 2009). "Indonesia Diambang Krisis Air Bersih". http://www.fajar.co.id/index.php?act=news\&id=58718

5. LeChevallier, Mark W. dan Au, Kwok-Keung (2004). Process Efficiency in Achieving Safe Drinking Water. World Health Organization (WHO).

6. IBM (2009) "IBM Makes Water Clean With Smarter, More Energy-Efficient Purification; New Desalination Membrane Developed in Collaboration with Central Glass, KACST Could Help Remedy World's Growing Water Shortage”. M2 Communications Ltd http://proquest.umi.com/pqdweb?did=1661519111\&sid=2\&Fmt=3\&clientId=672 $49 \& \mathrm{RQT}=309 \& \mathrm{VName}=\mathrm{PQD}$

7. McMahon, James P. "Are you worried about What's in Your Water? You Should Be.”. http://www.cleanairpurewater.com/ 
8. McMullan, Bob (2009). “AusAID: Water Report Highlights Need For Improved Sanitation and Water". M2 Communications Ltd. http://proquest.umi.com/pqdweb?did=1665500131\&sid=1\&Fmt=3\&clientId=672 $49 \& \mathrm{RQT}=309 \& \mathrm{VName}=\mathrm{PQD}$

9. Westjavawater (2005). "Cekungan Bandung Kritis (Bandung Basin Critical)”. http://westjavawater.blogspot.com/2005_03_01_archive.html

10. Westjavawater (2005). "168 Juta Penduduk belum Dapat Akses Air Bersih, Indonesia akan Krisis Air pada 2025 (No Clean Water Access, Water Crisis by 2025)”. http://westjavawater.blogspot.com/2005_03_01_archive.html

11. http://zeofilt.wordpress.com/2008/01/31/sistem-pengolahan-air-bersih/ 